\title{
Factors Related to Childbearing Willingness in the Women Attending the Health Centers in Arak, Iran (2019)
}

\author{
Rozita Ayazi ${ }^{1}$, Leila Amini ${ }^{2}$, Ali Montazeri ${ }^{3}$, Shima Haghani $^{4}$
}

\begin{abstract}
Background \& Aims: Childbearing is one of the most important components of population science and is more important than other demographic phenomena such as death and migration. Therefore, population policies in most countries are mainly focused on reducing or increasing fertility. Nowadays, we are facing a decrease in the tendency to have children in Iran, so that the total fertility rate (TFR) has decreased to 6.5 since mid-1978 and reached replacement level fertility in 1999 and is expected to decrease to $1.13 \%$ during $2020-2024$. According to the Low Population Growth Scenario released by the United Nations in 2010, if Iran continues replacement level fertility and has no plan to balance it, its population will reach 31 million in the next 80 years, and 47 percent will be the elderly over 60 years. These statistics and reports have caused serious concerns for the authorities, and the Supreme Leader of Iran has mentioned this issue several times and called for serious planning and legislation to get out of this situation. This has made population growth policies one of the priorities of the government. Meanwhile, according to previous researches, Markazi province is ranked as the third city in terms of the low desire of women to have children. This study aimed to determine the factors related to childbearing willingness in 18-45 -year old women referring to Arak health centers in 2019.
\end{abstract}

Materials \& Methods: This cross-sectional study was performed on 255 women aged 18-45 years, in 2019. The women were unwilling to have children. Data were collected from these women referring to 10 health centers in Arak who were selected through cluster sampling. Sampling was performed in January 2019. The data were collected through a questionnaire and included demographic information and variables related to childbearing willingness taken from Piltan et al.' questionnaire (2015) which included 78 items on religious beliefs (21 items), economic status (15 items), social participation (14 items), marital satisfaction (6 items), childbearing problems (7 items), gender socialization (5 items), fashionism (6 items), and fatalism (4 items), scored on a 5 -point Likert scale ranging from strongly agree (1) to strongly disagree (5). In order to assess the validity of the questionnaire, researchers extracted all the factors related to childbearing unwillingness from different researches and included them in the personal characteristics part of the questionnaire and a few faculty members assessed its reliability. Also, to evaluate the validity of the variables related to childbearing unwillingness, factor analysis methods and KMO test were used and all major components with a factor load of higher than 0.5 were confirmed, indicating a minimum acceptable correlation between factors and the items. In order to investigate the factors related to childbearing unwillingness in women referring to Arak health centers in 2019, independent t-test and chi-square were used and also to investigate the normal distribution of data, skewness, and kurtosis were used.

Results: According to the results, $9 \%$ of women unwilling to have children obtained low scores in terms of social participation, and $90.9 \%$ obtained medium and high scores. In addition, $9.8 \%$ of women unwilling to have children had low economic status, and $90.2 \%$ had medium and high levels. $3.9 \%$ of women unwilling to have children were at the low level in terms of marital satisfaction and $96 \%$ were at the medium and high levels. $2 \%$ of women unwilling to have children were at a low level in terms of childbearing problems and 98 were at the moderate and high levels. $38.8 \%$ of women unwilling to have children obtained low scores for gender socialization, and $61.2 \%$ obtained medium and high scores. $48.2 \%$ of these women obtained low scores for fatalism and $51.7 \%$ were

\footnotetext{
1. Department of Midwifery, Reproductive Health, and pregnancy, School of Nursing and Midwifery, Iran University of Medical Sciences, Tehran, Iran

2. Nursing Care Research Center (NCRC), Department of Midwifery, Reproductive Health, and pregnancy, School of Nursing and Midwifery, Iran University of Medical Sciences, Tehran, Iran (Corresponding author) Tel: 43651223 Email: amini.l@iums.ac.ir

3. Research Professor, Population Health Research Group, Health Sciences Research Institute, Jahad Daneshgahi, Tehran, Iran

4. Biostatistics, Nursing Care Research Center, Iran University of Medical Sciences, Tehran, Iran
} 
obtained median and high scores. In addition, $32 \%$ of the women had low scores in terms of fashionism, and $68 \%$ had medium and high scores. Also, the results of the study revealed that only $0.4 \%$ of the women participating in the study had low religious beliefs and $11.4 \%$ had average to high religious beliefs, and $88.2 \%$ were at the high level. Given that the upper and lower limits for the variables of social participation, economic status, marital satisfaction, childbearing problems are positive, so at $95 \%$ confidence interval, a direct relationship can be concluded between the variables of social participation, economic status, marital satisfaction, childbearing problems with childbearing unwillingness in women referring to Arak health centers at $95 \%$ confidence interval. Also, considering that the upper and lower limits for the variables of gender socialization and fatalism are negative, and the lower limit is negative for fashionism, so at $95 \%$ confidence interval, no significant relationship can be concluded between the variables of gender socialization, destiny and fashionism with unwillingness to have children. The results showed that only $0.4 \%$ of participants had low religious beliefs, $11.4 \%$ had average religious beliefs, and $88.2 \%$ reported high religious beliefs.

Conclusion: The decline in population growth in Iran is one of the most important problems and based on the results, women who do not want to have children have higher scores in terms of social participation, economic status, and marital satisfaction, so, it is necessary to teach them the importance of having children in health centers. On the other hand, in the present study, higher education level and social participation of women have been suggested as important factors related to women's unwillingness to have children. On the other hand, fertility problems were reported in most women who did not want to have children. Accordingly, proper management of active forces in society, including women, can prevent a sharp decline in fertility. This can be done by paying attention to family-oriented policies. In fact, providing low-cost care services for the children of mothers with higher social participation and making some laws in this area help women to combine maternal and social roles. As a result, women can engage in extracurricular activities such as education, employment, and social activities while caring for their children, and on the other hand, the tendency to have children may increase by reducing the problems of childbearing. One of the limitations of the present study was that self-report of marital satisfaction and economic status may have affected the accuracy of the results, which was beyond the control of the researcher.

Keywords: Fertility, Unwanted, Women

\section{Conflict of Interest: No}

How to Cite: Ayazi R, Amini L, Montazeri A, Haghani SH. Factors Related to Childbearing Willingness in the Women Attending the Health Centers in Arak, Iran (2019). Iran Journal of Nursing. 2021; 34(130):15-24.

Received: 6 March 2021

Accepted: 6 Jun 2021 


\title{
عوامل مرتبط با تمايل به فرزندآورى در زنان مراجعه كننده به پايكًاههاى سلامت شهر اراك،

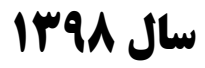

\author{
روزيتا ايازى'، ليلا امينى '، على منتظرى '، شيما حقانىع
}

جكيده

زمينه و هدف: فرزندآورى يكى از مؤلفهاى مهم علم جمعيت است كه نسبت بـه سـاير بديــهــاى جمعيتىى، از اهميت بيشترى برخوردار است. اين

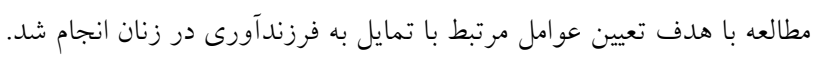

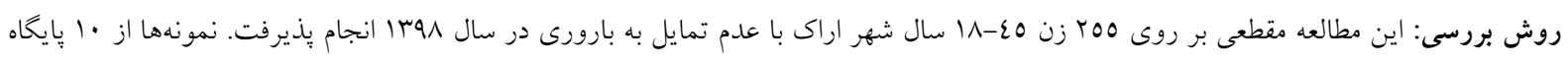

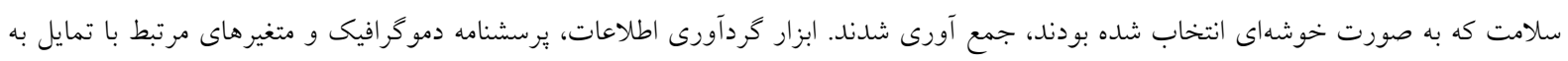

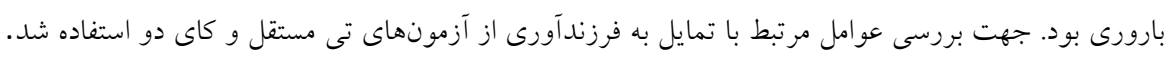

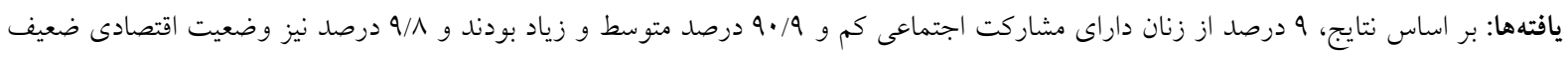

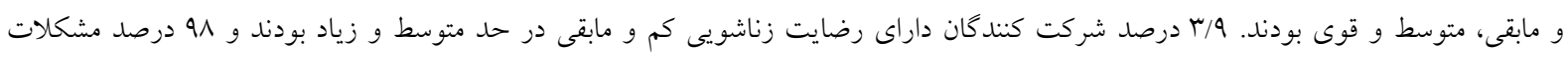

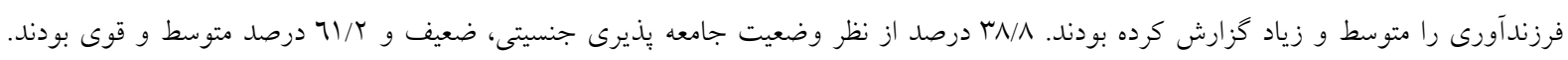

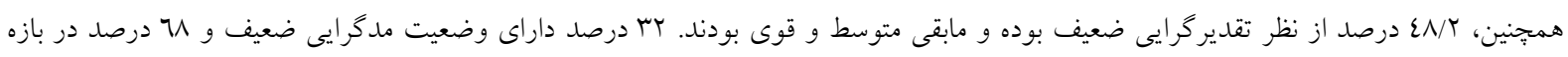

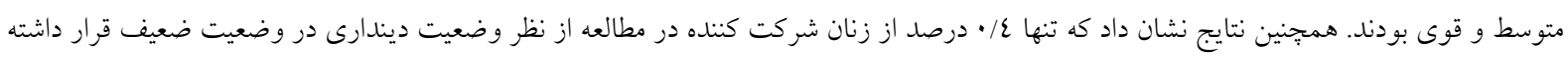
و ا ا درصد در بازه متوسط و M/T درصد نيز از نظر ديندارى قوى بودند.

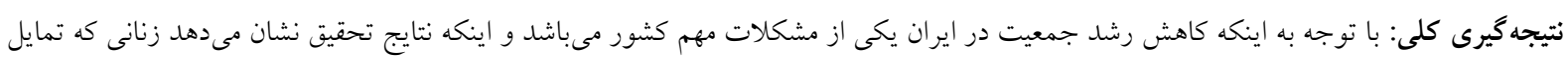

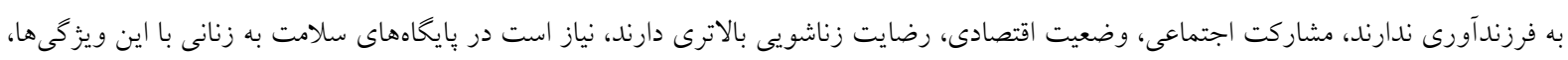
اهميت فرزندآورى آموزش داده شود.

كليد وازمها: بارورى، ناخواسته، زنان

تعارض منافع: وجود ندارد.

تاريخ دريافت:

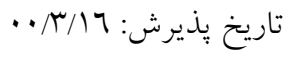

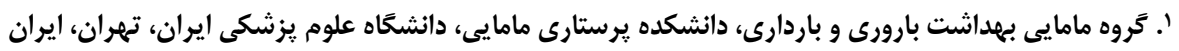

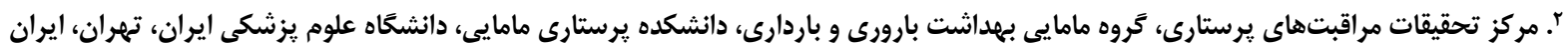

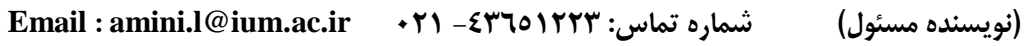

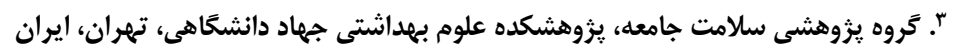

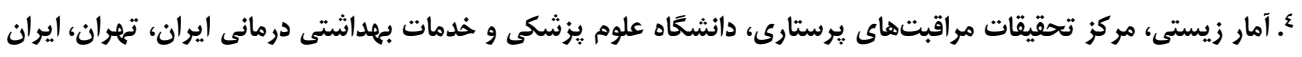


كه مسألدى جمعيت يكى از موضوعات مورد نظر برنامه

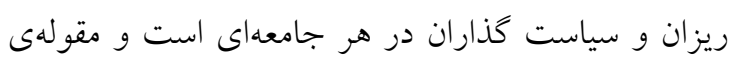

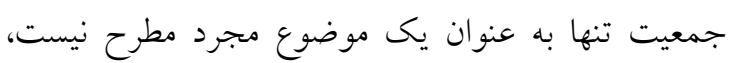
بلكه اين امر يك مسئلهى سياسى، اجتماعى، اقتصادى و

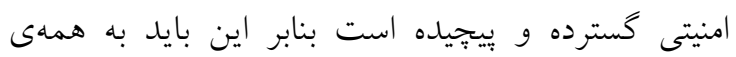

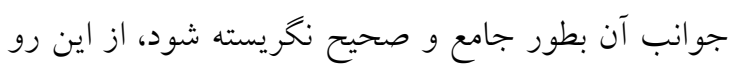

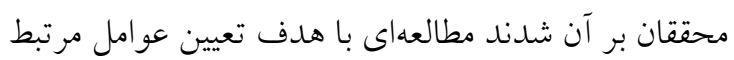

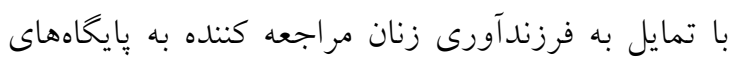
سلامت شهر اراى انجام دهند.

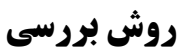

در اين موتش بروليى مطالعه مقطعى با كد اخلاق IR.IUMS.REC.1398.391 از كميته اخلاق دانشخاه

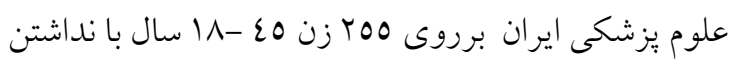

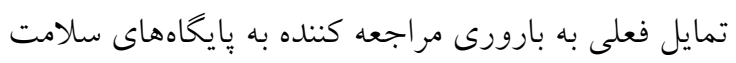

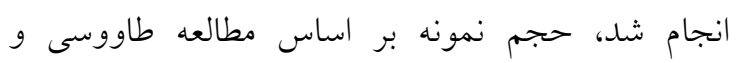

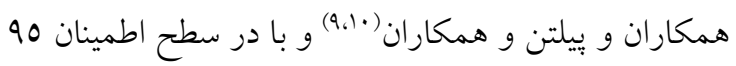

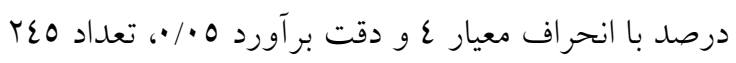

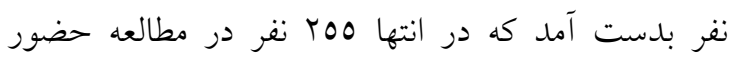

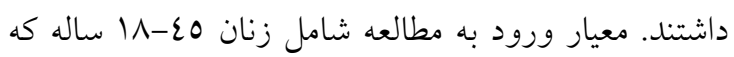

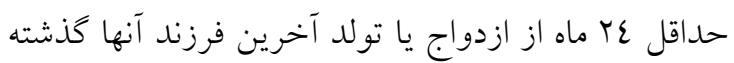

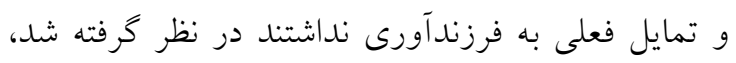

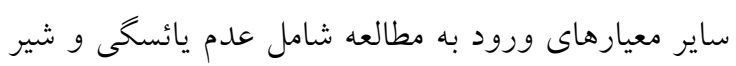

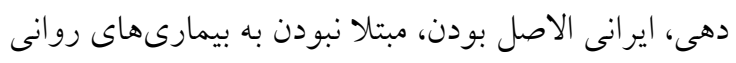

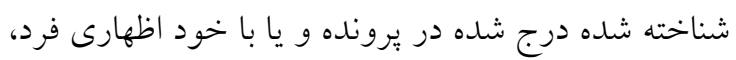

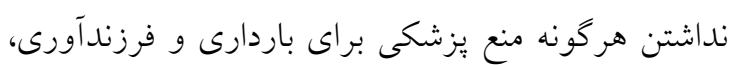

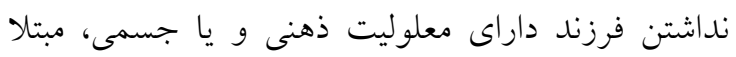

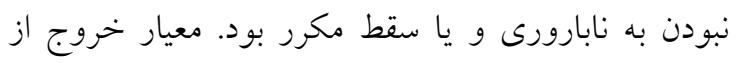

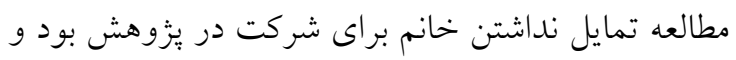

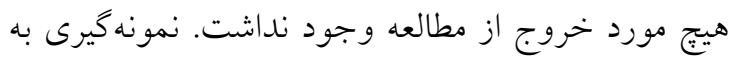

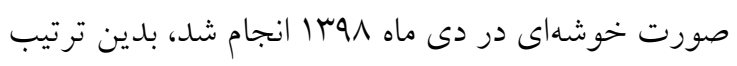

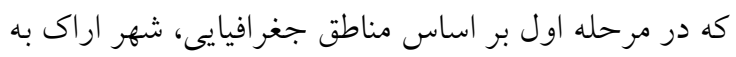

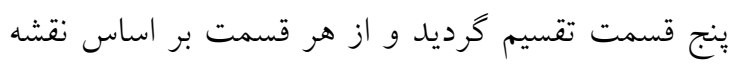

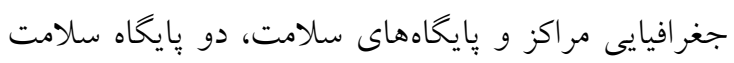

\section{مقلدمه}

فرزند آورى از مهم ترين مؤلفههاى جمعيتى است كه علاوه بر اين كه نقش عمدهاى در دخركونى كمى و كيفى جمعيت

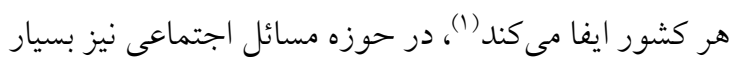

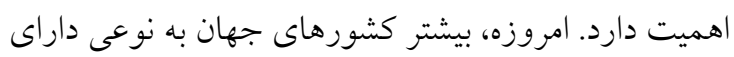

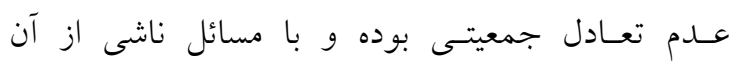

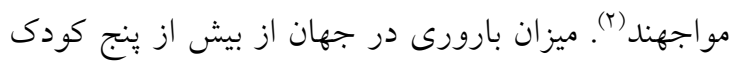

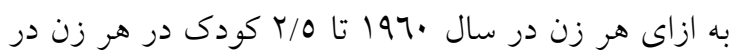

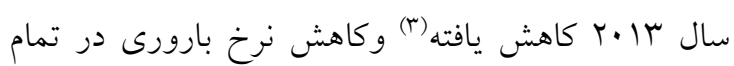

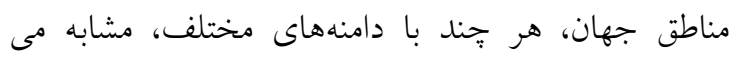
باشد (ع). در حالى كه برخى از كشورها با مشكلات هنات و مسائل

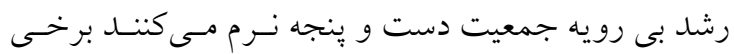

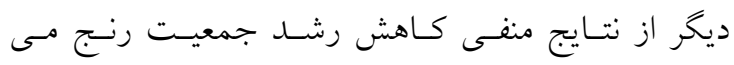

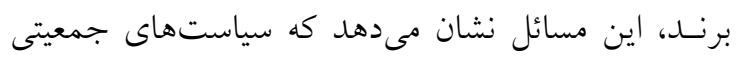

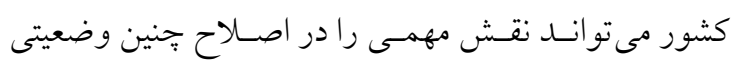
ايفا نمايد (0). ايران ازجمله كشورهايى اسـت كـه در جند دهأ اخير افت شديدى را در نرخ بارورى خود داشته است. كاهش بـارورى از حسـدود هفت فرزند به ازاى هر زن، در سال 09\%1، به حدود 1/9 فرزند در سال ه1/1 رسيده است، علاوه بر اين، استانهاى مختلف كشور به صورت همخون اين روند كاهش بارورى را طى نموده است (7).

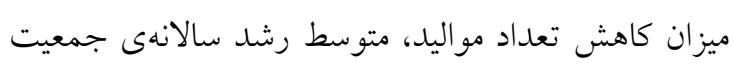
كشور را، از T/9 درصد در دهل درصد در دوره 90 كاهش رشد جمعيت در سـالهاى آينده مىتواند سبب تهايدهايى همجِون كاهش جمعيت فعال و مولد شود، اين امر مىتواند رشد اقتصادى و توسعه اجتماعى كه نيازمند وجود نيروى جوان، فعال و نوآور اسـت را نونيز تهلديد نمايد (^). نتايج يك تحقيق ملى در سال 90با در ايران نشان داد در بين اساستانى كه مورد بررسى قرار گرفته بود، استان مركزى با س/ بع درصد زنان متمايل به بارورى، سومين استان پايين از نظر تمايل به بارورى بوده و تمايل به فرزند

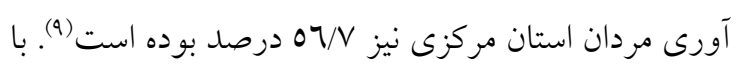

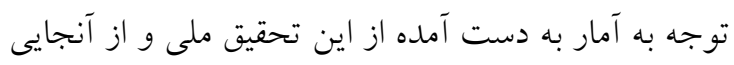


قوى) و امتياز ع تا م/9 (تقديرگر ايى ضعيف) در نظر كرفته

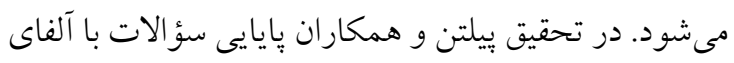

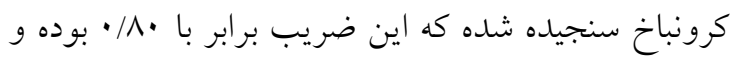

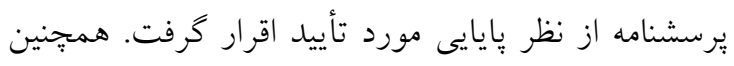

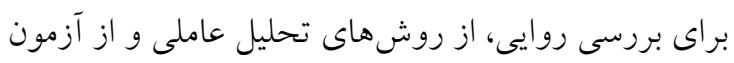
KMO

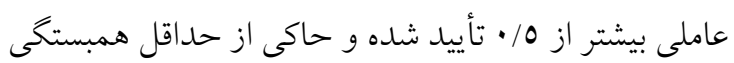

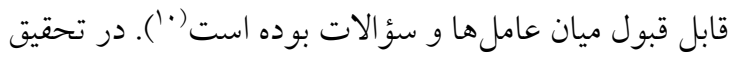
حاضر نيز روايى محتواى برسشنامه توسط پَند تن از

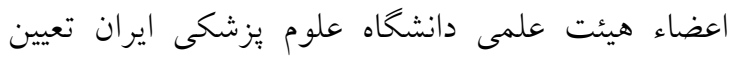

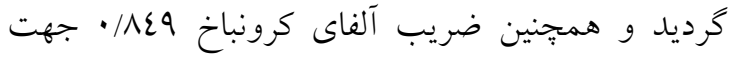

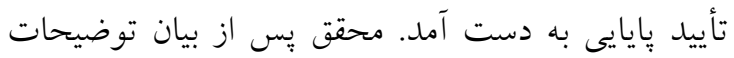

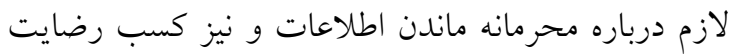

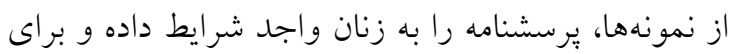
زنان كم سواد و بىسواد شخصاً اطلاعات را در يرسشنامه

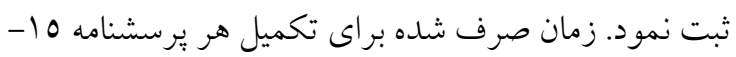

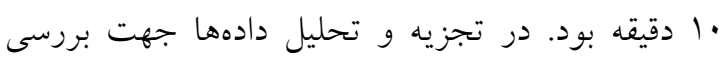

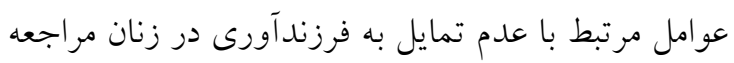

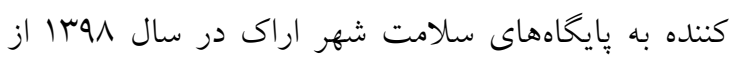

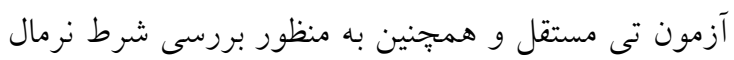

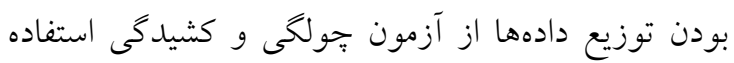

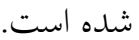

\section{يافتهها}

بيشترين تعداد زنان شركت كننده در اين مطالعه در محدوده

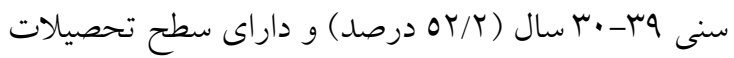
بالاتر از دييلم (T//)، خانه دار (79/2 درصد) و شيعه (99// درصد) بودند. هم:جنين بيشترين درصد اين زنان داراى منزل شخصى (7/7 درصد) بوده و 19-••ا سال از

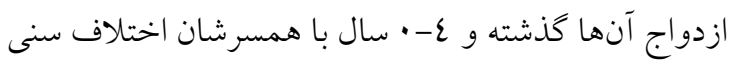
داشتند (T/ آه درصد). نتايج نشان مىدهد كه بيشترين

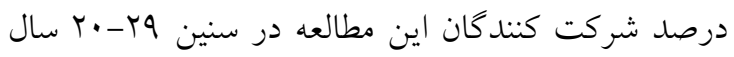

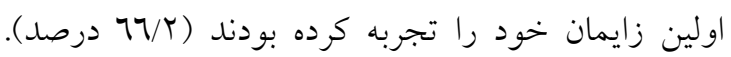

انتخاب شد (مجموعا · إيايخاه) و در مرحله دوم در هر

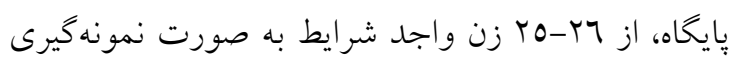
در دسترس، جمع آورى اطلاعات صورت كرفت.

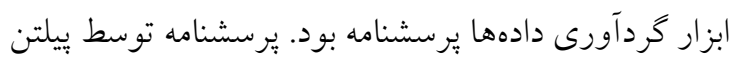

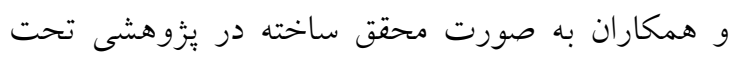

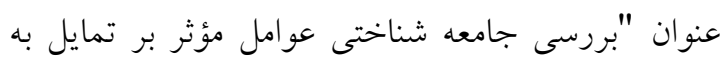

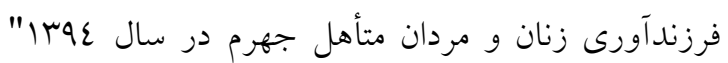

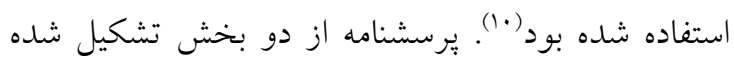
است بخش اول مشخصات فردى شامل سن زوجين، ميزان

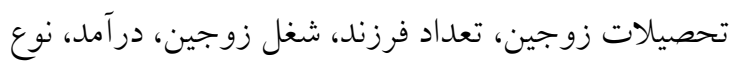

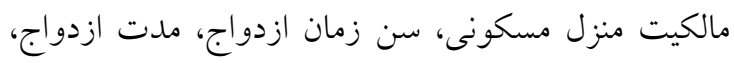
اختلاف سنى با همسر، سن زن در زمان تولد اولين فرزند، مذهب، جنسيت فرزندان و كافى بودن تعداد فرزندان

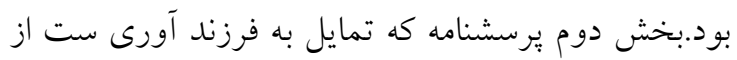
سؤال مربوط به وضعيت اقتصادى (10 سؤال)، VA

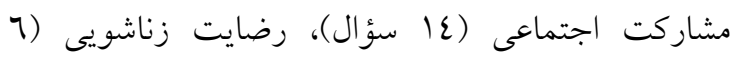

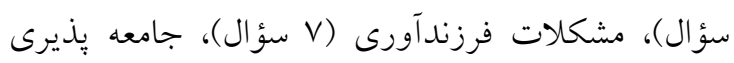

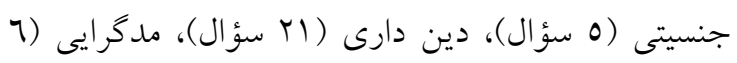

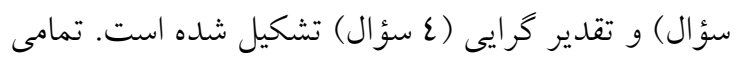
سؤالات اين بخش با مقياس ليكرت 0 سطحى از كاملاً

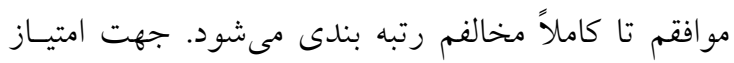

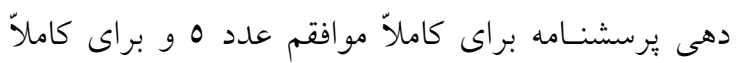

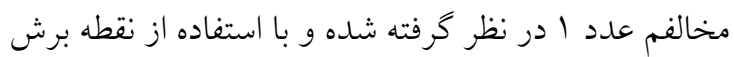

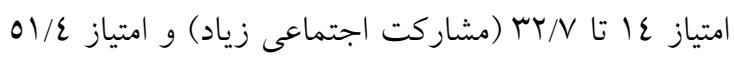
تا •V Vشاركت اجتماعى كم)؛ امتياز 00 تا VO (وضعيت اقتصادى قوى) و امتياز 10 تا Oم (وضعيت اقتصادى ضعيف) ،امتياز r تا • • (رضايت زناشويى زياد) و امتياز

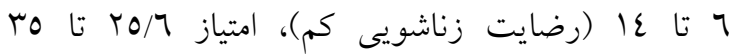

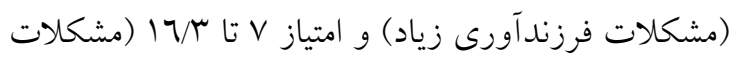

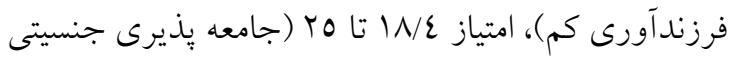
قوى) و امتياز 0 تا 11/V (جامعه بذيرى جنسيتى ضعيف)،

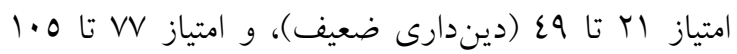
(ديندارى قوى)، امتياز r T تا • ب (مدكرايى قوى) و امتياز

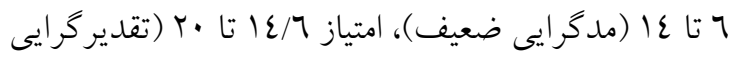


ديخر اطلاعات مربوط به مشخصات فردى در جدول شماره ا نشان داده شده است.

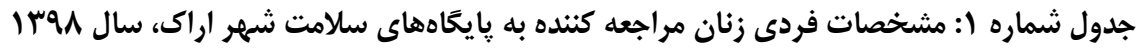

\begin{tabular}{|c|c|c|c|c|c|c|c|}
\hline درصد & فر اوانى & شخصات فردى & & درصد & فراوانى & \multicolumn{2}{|c|}{ مشخصات فردى } \\
\hline ro/1 & $7 \varepsilon$ & كمتر از •r & & $r \mu / l$ & 09 & كمتر از •r & \\
\hline$W / r$ & $\operatorname{lv} \varepsilon$ & $r \cdot-r q$ & & $O T / Y$ & 每 & $r \cdot-r q$ & \\
\hline $\mathrm{T} / \mathrm{V}$ & IV & • مَ و بالاتر & سن ازدواج & $r \varepsilon / V$ & r & • ع ع بالاتر & سن (سال) \\
\hline $1 \cdots$ & roo & كل & (سال) & $1 \cdots$ & roo & كل & \\
\hline \multicolumn{2}{|c|}{$r Y / \wedge O \pm \varepsilon / \varepsilon)$} & انحراف معيار 土 ميانگين & & \multicolumn{2}{|c|}{$r \varepsilon / \wedge 7 \pm \tau / 1 r$} & انحراف معيار 土 ميانگين & \\
\hline \multicolumn{2}{|c|}{$1 \varepsilon-\varepsilon$. } & بيشينه - كمينه & & \multicolumn{2}{|c|}{$r 1-\varepsilon 0$} & بيشينه - كمينه & \\
\hline ir & rA & كمتر از • كم & & $\varepsilon 1 / r$ & $1 \cdot 0$ & كمتر از •1 & \\
\hline $7 T / r$ & 100 & $r \cdot-r q$ & سن اولين & $\varepsilon r / 1$ & 11. & $1 \cdot-19$ & طول مدت ازدواج \\
\hline$r M / \Lambda$ & 01 & • م و بالاتر & زايمان & $10 / \mathrm{V}$ & $\varepsilon$. & 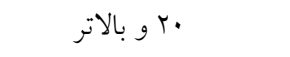 & (سال) \\
\hline $1 \cdots$ & $r \mu \varepsilon$ & كل & (سال) & $1 \cdots$ & roo & كل & \\
\hline \multicolumn{2}{|c|}{$r 0 / \cdot V \pm \varepsilon / V r$} & انحر اف معيار 土 ميانخين & & \multicolumn{2}{|c|}{$\mid r / 1 r \pm T / T$} & انحراف معيار 土 ميانخين & \\
\hline \multicolumn{2}{|c|}{ Ir-ru } & بيشينه - كمينه & & \multicolumn{2}{|c|}{$r-r q$} & بيشينه - كمينه & \\
\hline $71 / 7$ & loV & شخصى & وضعيت & $09 / 4$ & 101 & $\cdot-\varepsilon$ & \\
\hline ro/N & 91 & استيجارى & مالكيت منزل & ro/r & 9. & $0-9$ & \\
\hline$r / \Lambda$ & $v$ & ساير & 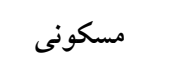 & $0 / 0$ & $1 \varepsilon$ & ل الم و بيشتر & اختلاف سنى با همسر \\
\hline $1 \cdots$ & roo & كل & & $1 \cdots$ & roo & كل & 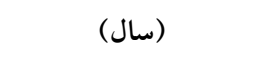 \\
\hline $79 / 2$ & IVV & خانهدار & وضعيت & \multicolumn{2}{|c|}{$\varepsilon / T \varepsilon \pm T / \eta \Lambda$} & انحر اف معيار 土 ميانخين & \\
\hline$r \cdot / 7$ & vı & 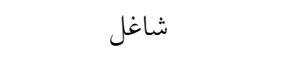 & اشتغال & \multicolumn{2}{|c|}{$\cdot-12$} & بيشينه - كمينه & \\
\hline $1 \cdots$ & roo & كل & & $\Lambda / 7$ & Tr & بىسواد و ابتدايى & \\
\hline $99 / r$ & ror & شيعه & & $\varepsilon 1 / r$ & 1.0 & متوسطه تا دييلم & سطح تحصيلات \\
\hline$\cdot / \wedge$ & r & سنى س & مذهب & $0 . / r$ & $M \Lambda$ & بالاتر از دييلم & \\
\hline $1 \cdots$ & roo & 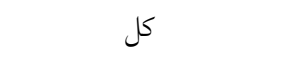 & & $1 \cdots$ & roo & كل & \\
\hline
\end{tabular}

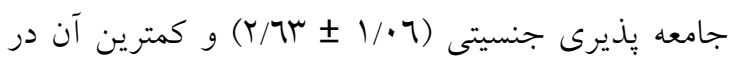

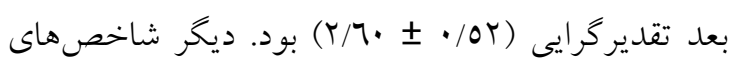

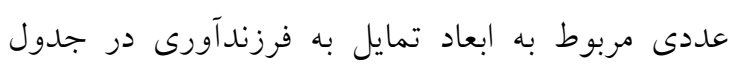
شماره r نمايش داده شده است.
بر اساس يافتههاى جدول شماره T، بيشترين ميانخين ابعاد

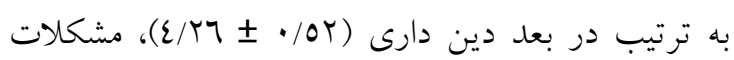

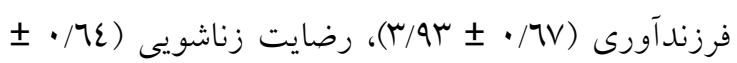

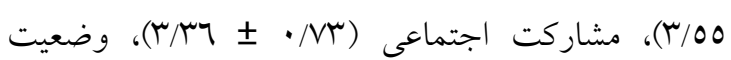

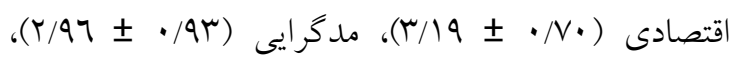


جدول شماره ז: شاخصهاى عددى ابعاد تمايل به فرزندآورى در زنان مراجعه كننده به بايغاه هاى سلامت شهر اراك، سال ^هسا

\begin{tabular}{|c|c|c|c|c|c|c|c|c|}
\hline \multicolumn{4}{|c|}{ بر مبناى 0-1 } & \multicolumn{4}{|c|}{ بر مبناى نمره كل } & \multirow[t]{2}{*}{ ابعاد تمايل به فرزند آورى } \\
\hline بيشينه & كمينه & انحر اف معيار & ميانكين & بيشينه & كمينه & انحر اف معيار & ميانكين & \\
\hline 0 & $1 / 7 V$ & .104 & $\varepsilon / \Gamma 7$ & 1.0 & ro & $1 . / 97$ & 19/2V & ديندارى \\
\hline 0 & r & $\cdot / 7 \mathrm{~V}$ & $r / q r$ & ro & $1 \varepsilon$ & $\varepsilon /\rceil$ & $T V / \varepsilon q$ & مشكلات فرزندآورى \\
\hline 0 & $1 / 0$. & $\cdot / 7 \varepsilon$ & $r / 00$ & $r$. & 9 & $r / \Lambda r$ & $r / \pi r$ & رضايت زناشويى \\
\hline 0 & $1 / 7$ & $\cdot N r$ & $r / \mu ר$ & $v \varepsilon$ & $r \varepsilon$ & $1 \cdot / 9$ & 0.1 .0 & مشاركت اجتماعى \\
\hline 0 & 1 & $\cdot N$ & $r / 19$ & $v \cdot$ & $1 \varepsilon$ & $9 / N V$ & $\varepsilon \varepsilon N r$ & وضعيت اقتصادى \\
\hline 0 & 1 & . $/ 9$ r & $r / 97$ & $r$. & 7 & $0 / 71$ & IVNT & مدكرايى \\
\hline 0 & 1 & $1 / \cdot 7$ & $r / \pi$ & ro & o & $0 / 79$ & $\mid r / 1 \varepsilon$ & جامعه يذيرى جنسى \\
\hline 0 & 1 & . 194 & $r / \nearrow$. & $r \cdot$ & $\varepsilon$ & $r / N r$ & $1 \cdot / \varepsilon$ & تقدير ترايى \\
\hline
\end{tabular}

زنان شركت كننده در مطالعه، در سطح متوسط بود. اين در

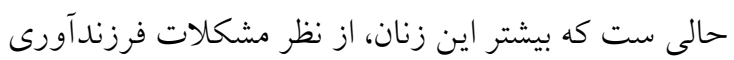

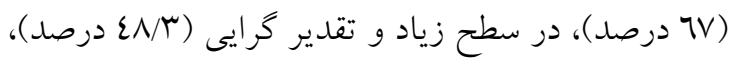
در سطح ضعيف قرار داشتند.
بر اساس يافتههايى كه در جدول شماره ب مشاهده مىشود،

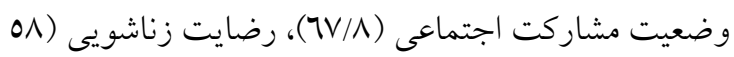

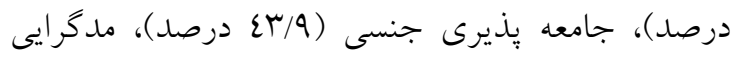
(

جدول شماره س: توزيع فراوانى سطوح تمايل به فرزندآورى و ابعاد آن در زنان مراجعه كننده به يايعاههاى سلامت شهر اراك، سال هوسا

\begin{tabular}{|c|c|c|c|c|c|c|c|}
\hline درصد & فراوانى & سطوح & ابعاد & درصد & فراوانى & سطوح & ابعاد اد \\
\hline $9 / 1$ & ro & ضعيف (10 - 10) & وضعيت اقتصادى & $9 / \cdot$ & r & كم (IE-MY/V) & مشاركت \\
\hline $00 / \mathrm{N}$ & IET & متوسط (00-00) & & $T V / \Lambda$ & ivr & متوسط (YT/V-01/L) & اجتماعى \\
\hline$r \varepsilon / 0$ & м & قوى (100-V0) & & $r r / l$ & 89 & زياد (•V-ع//0) & \\
\hline $1 \cdots$ & roo & جمع كل & & $1 \cdots$ & roo & جمع كل & \\
\hline$r / \cdot$ & o & كم (V-1T/r) & مشكلات & $r / 9$ & 1. & كم (1-1) & رضايت \\
\hline ri/ & va & متوسط (1/T-ro/T) & فرزندآورى & $O N / \cdot$ & I乏A & متوسط (YY-Y (I) & زناشويى \\
\hline $\mathrm{TV} / \cdot$ & $|v|$ & زياد (ro/7-ro) & & rN/I & $9 \mathrm{~V}$ & زياد (·r-rYr) & \\
\hline $1 \cdots$ & roo & جمع كل & & $1 \cdots$ & roo & جمع كل & \\
\hline$\varepsilon \Lambda / \Gamma$ & kr & ضعيف (4/T-ع) & تقدير گرايى & rN/A & 99 & ضعيف (N/11) & جامعه بذيرى \\
\hline$r_{N / \varepsilon}$ & 91 & متوسط (q/T/Y) & & $\varepsilon \Gamma / q$ & $11 \%$ & متوسط (I/N-11/2) & جنسى \\
\hline $1 \pi / \pi$ & $r \varepsilon$ & قوى (•r/Z/T) & & $I V / r$ & $\varepsilon \varepsilon$ & قوى (N/L-YO) & \\
\hline \multirow[t]{5}{*}{$1 \ldots$} & roo & جمع كل & & $1 \cdots$ & roo & جمع كل & \\
\hline & & & & $r T / Y$ & $\Lambda T$ & ضعيف (ع |-7) & مدگرايى \\
\hline & & & & $\varepsilon \varepsilon / V$ & $11 \varepsilon$ & متوسط (YY-Y (I) & \\
\hline & & & & $r \mu / 1$ & 09 & قوى (•rY-r) & \\
\hline & & & & $1 .$. & roo & جمع كل & \\
\hline
\end{tabular}


فرزندآورى داشتند، مشكلات فرزندآورى را زياد مى نق نقان دانستند. نتايج تحقيق Alfaraj نيز نشان داد كه از نظر فرزئن دختران دانشجوى عربستان، مادر بودن زندكى آنها را در

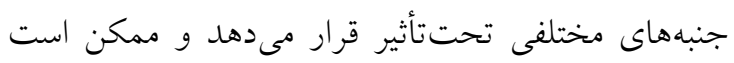

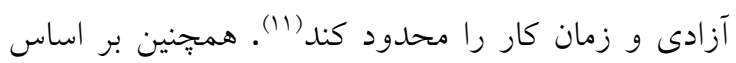
نتايج تحقيق مير ابى و همكاران در شهرهاى تهران و مشهد،

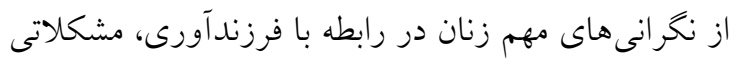

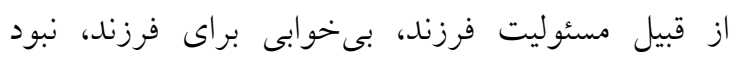

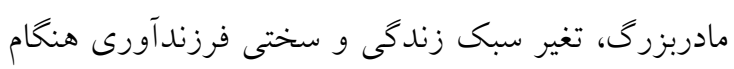

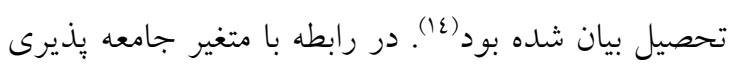

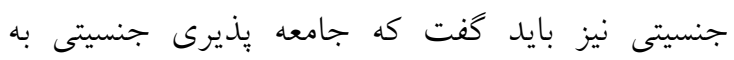

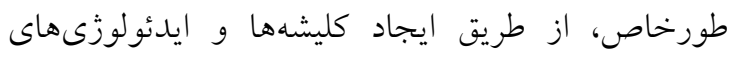
جنسيتى، بر ساختمان ذهنى و رفتارهاى ناشى ازآن تأثير

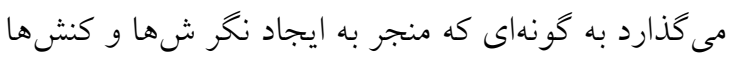

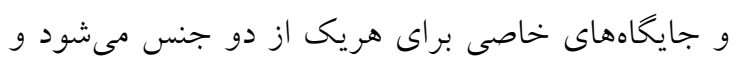
مى تواند رفتارهاى متفاوتى در زوجين ايجاد كند (10)، به به هرئ

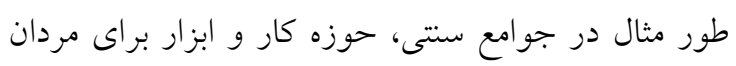

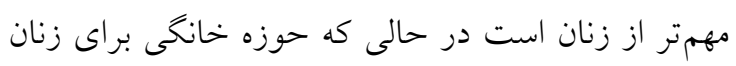

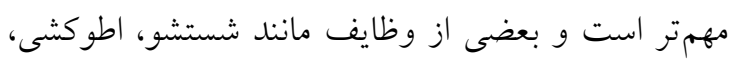

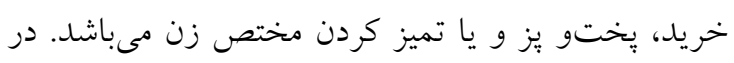

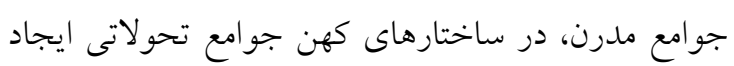

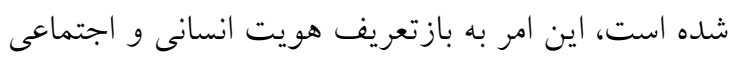

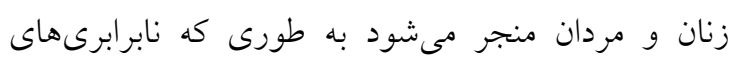

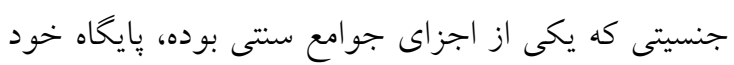

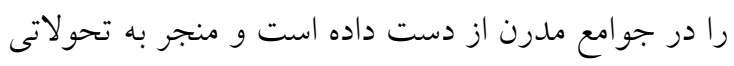
در الكوى جامعه يذيرى جنسيتى شده است (17). در نتايج

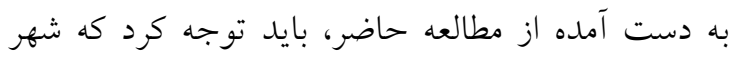

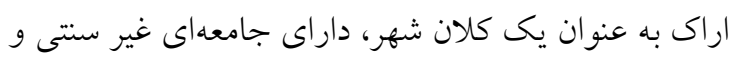

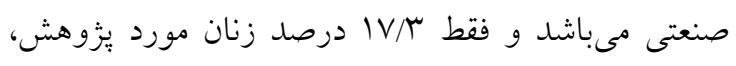

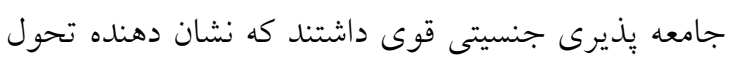

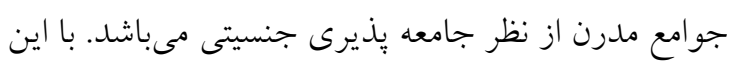

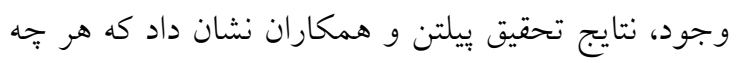

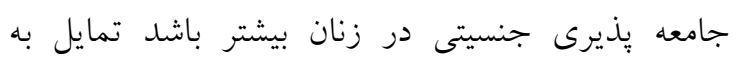

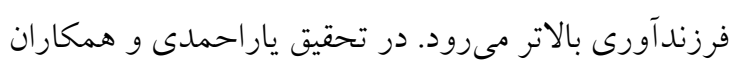

بحث و نتيجه تيرى

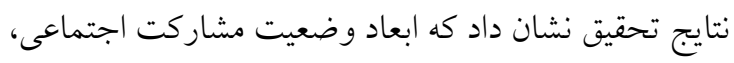

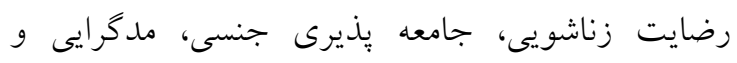

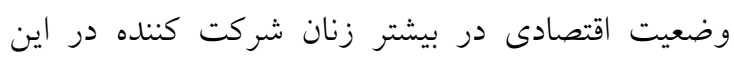
مطالعه، در سطح متوسطى، تمايلشان به فرزندآورى را توصيف مىنمود. اين در حالى بودكه بيشتر اين زنان،

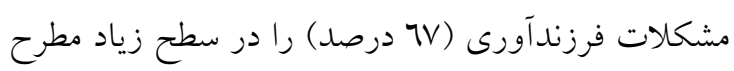

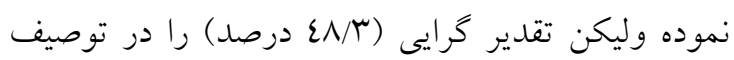
تمايلشان به فرزندآورى در سطح ضعيفى دخيل مى دانستند.

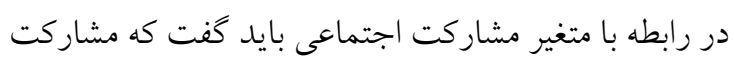

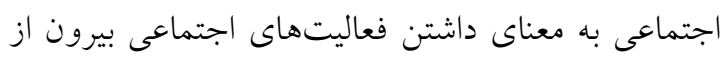

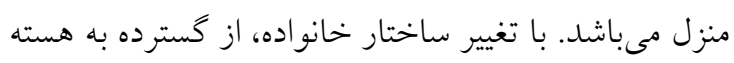

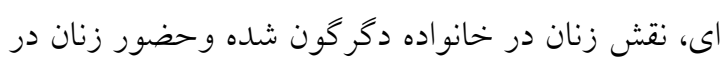
عرصههاى اجتماعى افزايش يافته است. به دنبال تغيير

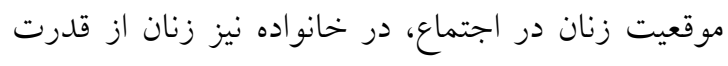

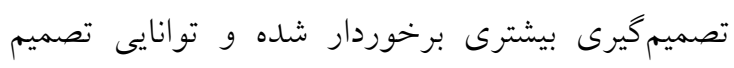

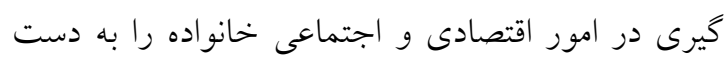

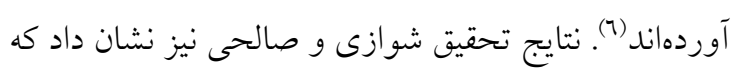

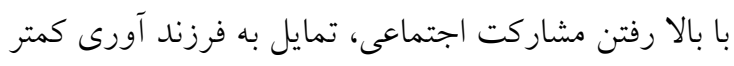

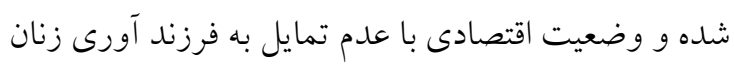

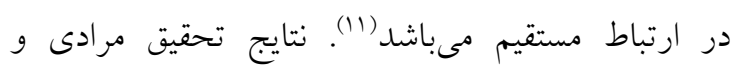

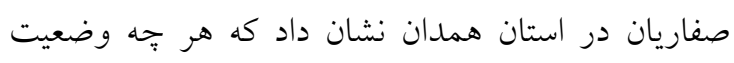

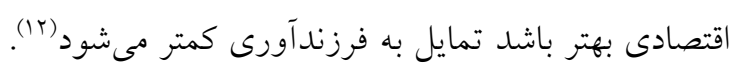

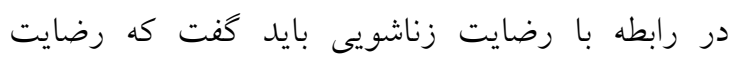

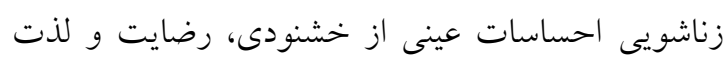
تجربه شده توسط زن و شوهر، زمانى كه همه جنبه آناى

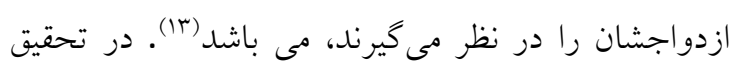

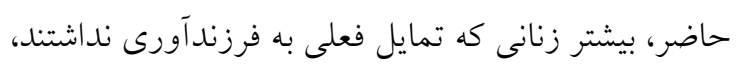

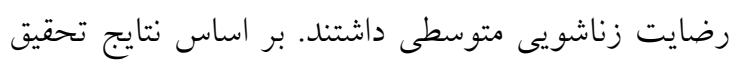

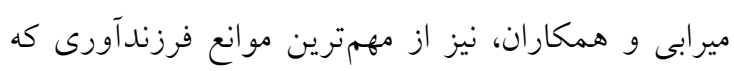

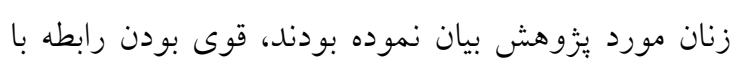

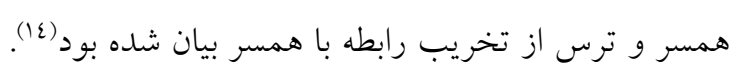

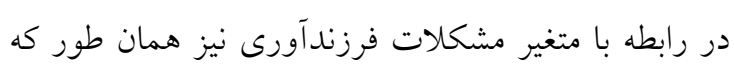

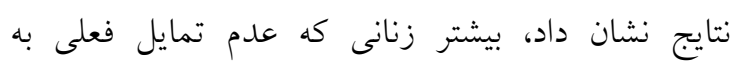


كاهش شديد ميزان بارورى جلو گيرى به عمل آورد. اين

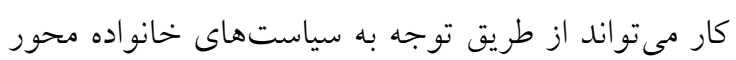

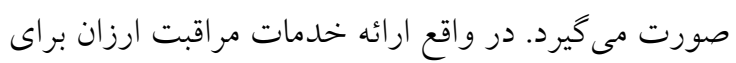

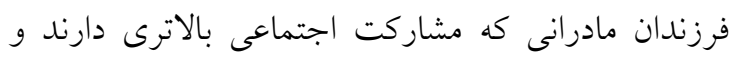

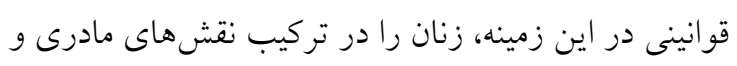

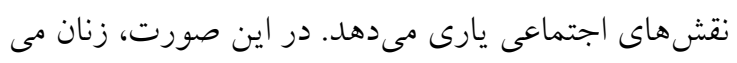

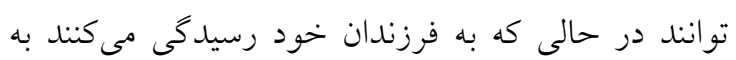

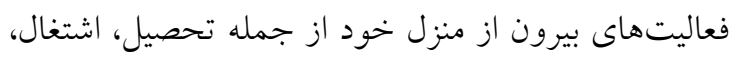

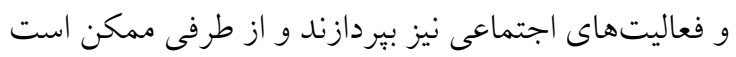

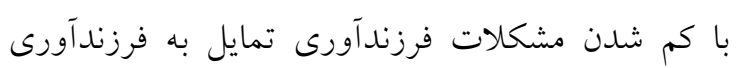

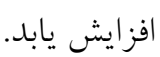
از جمله مححدوديتهاى يزوهش حاضر اين است كه خود

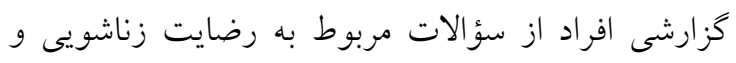
وضعيت اقتصاد ممكن است بر صحت و دقت نتائ نترايج تأثير گذار بوده باشد. از طرفى، مراجعه كنند أنان به بايڤاه

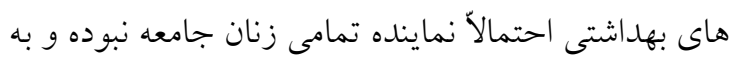
نظر مىرسد كه زنان شاغل و زنان طبقات اقتصادى نهاى نهان

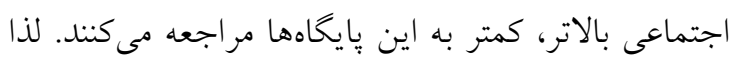
تعميم يذيرى نتايج بايستى با احتياط بيشترى صورت كيرد.

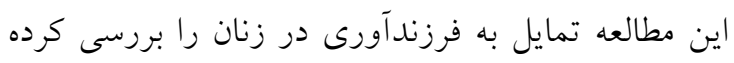

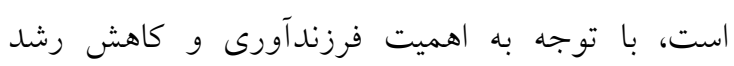
جمعيت در ايران، بيشنهاد مى شود تحقيقى با همين عنوان در گروه هدف مردان انجام گردد.

تعارض منافع: هيج گونه تعارض منافع توسط نويسندگان بيان نشده است.

\section{تقدير و تشكر}

اين مقاله حاصل از بايان نامه كارشناسى ارشد آموزش تُش

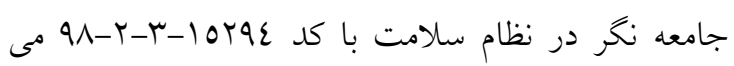

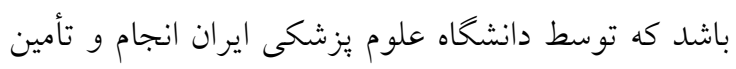

$$
\text { مالى شده است. }
$$

نيز بين جامعه يذذيرى جنسيتى و كرايش به فرزند آورى

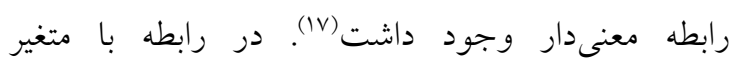

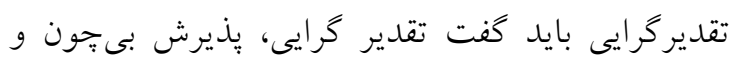

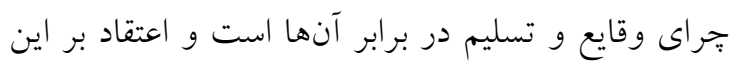
است كه وقايع خارج از حيطه تسلط انسان اتفاق مى افتد.

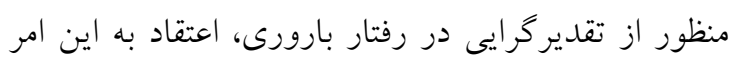
است كه فرزندآورى، خارج از اختيار فرد و كاملاً خواسته دئه

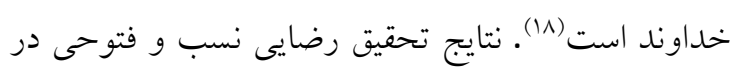

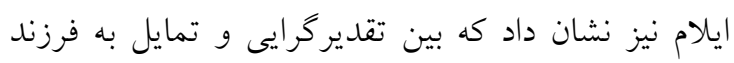

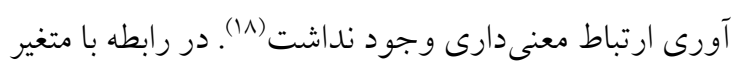
مدكرايى مىتوان كفت كه مدگرايى از جمله مطرحترين مسائل نويديد اجتماعى در عصر حاضر به شمار مى مرود،

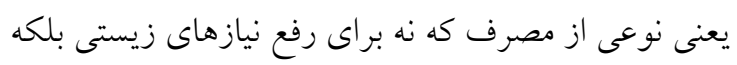

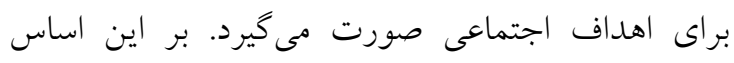

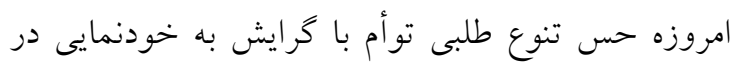

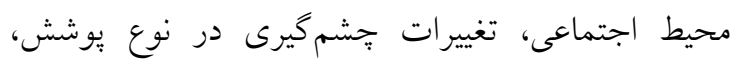

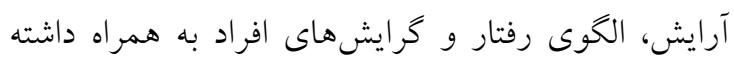

است (19)

اين تحقيق به منظور بررسى عوامل مرتبط با تمايل به

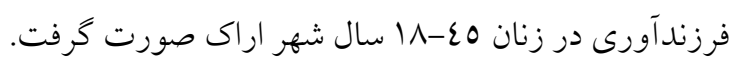

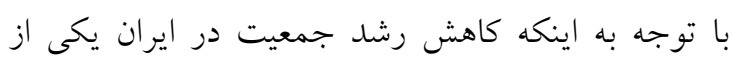

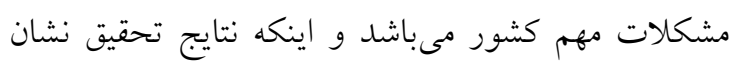

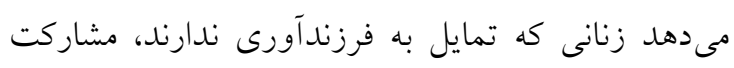

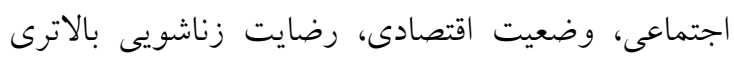

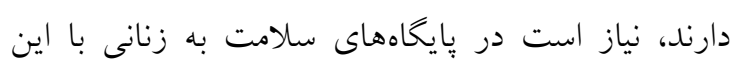

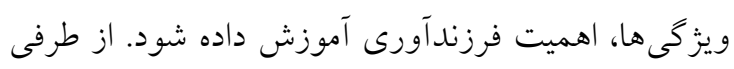
در يزوهش حاضر، افزايش سطح تحصيلات و مشاركت اجتماعى زنان به عنوان عامل مهم مرتبط با عدم تمايلات

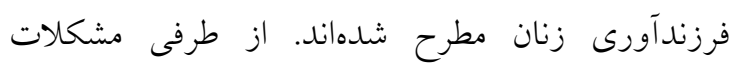

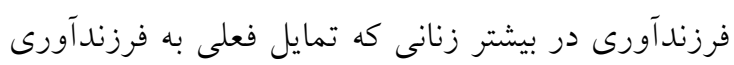

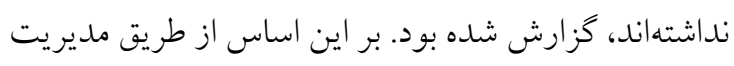

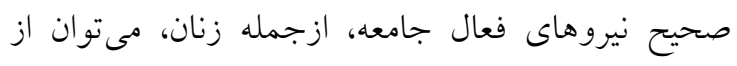




\section{References}

1. Khadivzadeh T, Arghavani E, Shakeri MT. Attitude toward governmental incentives on childbearing and its relationship with fertility preferences in couples attending premarital counseling clinic in health centers in Mashhad. Journal of Mazandaran University of Medical Sciences. 2015;24(120):1-13. [Persian]

2. T Tavousi M, Motlagh ME, Eslami M, Haerimehrizi A, Hashemi A, Montazeri A. Fertility desire and its correlates: A pilot study among married citizens living in Tehran, Iran. Payesh (Health Monitor). 2015;14(5):697-702. [Persian]

3. De Silva T, Tenreyro S. Population control policies and fertility convergence. J Econ Perspec. 2017;31(4):205-8.

4. Pantazis A, Clark SJ. A parsimonious characterization of change in global age-specific and total fertility rates. PloS one. 2018;13(1):e0190574.

5. Wang D, Chi G. Different places, different stories: A study of spatial heterogeneity of countylevel fertility in China. Demographic research. 2017;37:493.

6. Abbasishavazi M, Khani S. Economic insecurity and fertility: case study of married women in Sanandaj District. Journal of Population Association of Iran. 2014 22;9(17):37-76. [Persian]

7. Fathi E. The Phenomenon of Population Aging in Iran. Ijoss Iranian Journal of Official Statistics Studies. 2020;30(2):387-413. [Persian]

8. Razavizadeh N, Ghafarian E, Akhlaqi A. Grounds for low child seeking and delay in child bearing (case study: Mashhad women). Scientific Journal Management System. 2015;8(31):73-98. [Persian]

9. Tavousi M, Haerimehrizi A, Sadighi J, Motlagh ME, Eslami M, Naghizadeh F, Anbari M, Hasemi A, Montazeri A. Fertility desire among Iranians: a nationwide study. Payesh. 2017;16(4):40110. [Persian]

10. Piltan F, Rahmanian M. Investigating factors affecting the tendency toward childbearing among married men and women (case of study: men and women aged 25 to 45 years old in Jahrom). Journal of Iranian social development studies. 2015;7(2):121-34. [Persian]

11. Alfaraj S, Aleraij S, Morad S, Alomar N, Al Rajih H, Alhussain H, Abushrai F, Al Thubaiti A. Fertility awareness, intentions concerning childbearing, and attitudes toward parenthood among female health professions students in Saudi Arabia. Int J Health Sci. 2019;13(3):34.

12. Moradi A, Saffarian M. Sociological study of people's attitudes toward childbearing in Hamadan province. Population Magazine. 2019;25(103-104):59-90. [Persian]

13. Masoumi SZ. The status and marital satisfaction factors in nulliparous pregnant females attending clinics in Asadabad city during years 2015 and 2016. Avicenna Journal of Nursing and Midwifery Care. 2017;25(1):52-9. [Persian]

14. Mirabi S, Mirzaei H, Hassani Darmian GR. A Phenomenological Study on Married Women Awareness of Childbearing. Journal of Applied Sociology. 2020;31(3):1-20. [Persian]

15. Azadeh MA, Arami S. A Study on Gender Socialization and Behavior in social dilemma A Study on Gender Socialization and Behavior in social dilemma. Women's Studies Sociological and Psychological. 2016;14(1):7-39. [Persian]

16. Cerrato J, Cifre E. Gender inequality in household chores and work-family conflict. Frontiers in psychology. 2018;9:1330.

17. Yarahmadi A, Feizi M, Karimi H. Determinants of Kurdish Women's Sub-Replacement Fertility. The Women and Family Cultural Education. 2019:14(48):97-120. [Persian]

18. Rezaeinasab Z, Fotoohi S. Socio-cultural Factors Influencing the Fertility of Married Women (49-15) in Ilam City. Ilam Culture. 2017;18(54-55):122-33. [Persian]

19. Jahanbakhshganjeh S, Jafari N. The Sociological Explanation of Fashionism, From the Female Students' Viewpoint in Kharazmi University. Intercultural Studies Quarterly. 2018;13(34):87-112. [Persian] 